\title{
QUESTÕES DE FRONTEIRA'
}

\section{Sobre uma antropologia da história}

\author{
LILIA K. MORITZ SCHWARCZ
}

\section{RESUMO}

$\mathrm{O}$ artigo investiga como a antropologia reflete sobre os processos históricos. Com base na análise de diversas vertentes teóricas, procura analisar a importância que a história desempenha em cada tradição, bem como reconhecer o papel que a reflexão historiográfica assumiu na própria constituição da antropologia como disciplina. A partir do diálogo com a obra de Lévi-Strauss, Marshall Sahlins e Thomas Mann, entre outros, a autora discorre sobre a noção de tempo não apenas em culturas distantes, mas também na sociedade ocidental.

PALAVRAS-CHAVE:antropologia; história; alteridade; temporalidade.

\section{SUMMARY}

The article investigates the way anthropology deals with historical processes. Focusing on a wide range of theoretical schools, it tries to analyze the role played by history in each tradition, as well as understand how it helped build anthropology as a discipline. Taking as guideline the work of authors such as Lévi-Strauss, Marshall Sahlins and Thomas Mann, the author discusses the notion of time not only in distant cultures, but also in occidental society.

KEYWORDS: anthropology; history; temporality; otherness.

[1] Este ensaio foi apresentado originalmente sob a forma de uma "prova oral de erudição", em concurso para professor titular, realizado pelo Departamento de Antropologia Social da Universidade de São Paulo. A aula foi realizada no dia 9 de março de 2005 e procurou, justamente, recuperar momentos dessa fronteira entre antropologia e história, privilegiando a primeira disci-
HISTÓRIA ANTROPOLÓGICA OU ANTROPOLOGIA DA HISTÓRIA?

Não é de hoje que se debatem as relações entre história e antropologia. Se tal afirmação faz sentido para ambos os lados, é possível dizer, sobretudo no caso da antropologia - e já em um contexto de institucionalização da disciplina -, que a oposição entre sincronia e diacronia mostrou-se fundamental para a delimitação de modelos, perfis e recortes. 
Proponho, então, investigar alguns momentos em que a antropologia, enquanto disciplina, refletiu sobre a história. Ou melhor, como algumas escolas de antropologia - e certos autores - dialogaram com várias histórias: um modelo ocidental de história (digamos assim, e de forma provisória), pautado pela cronologia e pela comprovação documental; uma história tal qual os historiadores a fazem (a disciplina histórica); uma história entendida como categoria social (e que me remete à noção de temporalidade); ou a crítica a uma certa "Filosofia da História", o que permitirá pensar no conceito de historicidades, qual seja: diante da experiência etnográfica, não há como entender história no singular².

Minha intenção, assim, é alinhavar "movimentos dessa fronteira", sem canonizar autores nem dar um tom por demais encadeado ao argumento. Com efeito, o risco de uma visão evolutiva está presente em diversas correntes da História das Idéias, que supõem uma sucessão de sistemas filosóficos ${ }^{3}$, deixando "escapar o essencial: o próprio conteúdo das teorias historiadas"4.

Mas comecemos do início. É possível definir história como um conceito universal, já que a experiência comum da passagem do tempo é consensual, mas também particular: na dimensão dos eventos e quando o acontecimento é culturalmente valorizado. A história pode, ainda, ser tomada como uma disciplina, ou como uma categoria fundamental. Nesse último sentido, e nos termos de Durkheim, estaríamos lidando com uma "categoria básica do entendimento", um a priori: não há sociedade que não construa sua noção de tempo, mas cada cultura a realiza empiricamente de forma diversa ${ }^{5}$.

Poderíamos opor, também, duas noções mais óbvias de tempo e, como veremos, de história. Assim como as coisas vivas nascem, crescem e morrem - e, portanto, mudam -, também certos fenômenos da natureza se repetem (a semana; as estações; o dia que vira noite, e viceversa). Um paralelo pode ser feito com a famosa distinção entre "sociedades com ou sem história": as que se definem pela mudança ou pela reiteração - nesse último caso, as nomeadas "sociedades frias" (na versão de Lévi-Strauss), "estagnantes" (na concepção de Claude Lefort $)^{6}$. Mas esse debate foi abandonado faz algum tempo, ou pelo menos o mal-entendido que o circundava. Lefort mostrou como teria procurado não por "realidades empíricas", mas antes por modelos; e Lévi-Strauss explicitou que tal classificação servia, apenas, para assinalar diferenças entre culturas: definia somente dois estágios que, nos termos de Rousseau, "não existem, não existiram, jamais existirão"7.

Como se pode notar - e parafraseando Lévi-Strauss - , a história é "boa para pensar" ${ }^{8}$. Assim como se estudam parentescos, rituais, simbologias, também a história permite prever como a humanidade é una, mas variada em suas manifestações.

Hora de ajustar o foco. Não é meu objetivo selecionar uma, entre essas tantas definições, mas antes pensar como a antropologia vem plina; área na qual se realizava o concurso. Como se verá, a pergunta que orienta o ensaio visa entender de que maneira a produção antropológica dialogou com "várias histórias". Nesse sentido, propositadamente não se fez o caminho oposto, o qual implicaria perguntar quais foram "as antropologias" com que a historiografia (seja ela inglesa ou francesa) dialogou. Esse debate levaria a outras indagações e escaparia aos propósitos e limites desse estudo.

[2] Vide, nesse sentido, Gaboriau, M. "Antropologia estrutural e história", in Lima, L. C. (org.). O estruturalismo de Lévi-Strauss. Petrópolis: Vozes, 1968; Goldman, M. "Lévi-Strauss e os sentidos da história". Revista de Antropologia, vol. 42, n. 1-2, São Paulo, USP/ FFLCH, Depto. de Antropologia, 1998; e idem. "Lévi-Strauss e os sentidos da história", in idem. Alguma antropologia. Rio de Janeiro: Relume Dumará, 1999.

[3] No lugar de uma "História das Idéias", François Châtelet, em sua História da filosofia (Rio de Janeiro: Zahar, 1972), propõe uma "Geografia das Idéias".

[4] Goldman, M. Razão e diferença. Rio de Janeiro: Editora da UFRJ, 1994.

[5] Vide Durkheim, É. "Representações individuais e representações coletivas" (1898), in Sociologia e filosofia. Rio de Janeiro: Forense, 1988. Sugiro também a leitura do artigo de Pontes, Heloisa. "Durkheim: uma análise dos fundamentos simbólicos da vida social e dos fundamentos sociais do simbolismo". Cadernos de Campo, ano 3, n. 3, 1993, pp. 89-102.

[6] Lévi-Strauss, C. "História e etnologia", in Antropologia estrutural. Rio de Janeiro: Tempo Brasileiro, 1975; idem. "História e etnologia", Textos Didáticos, n. 24, 1996; Lefort, C. As formas da história. São Paulo: Brasiliense, 1979.

[7] Idem. "Histoire et ethnologie", Annales E.S.C., vol. 38, n. 6, 1983, p. 1219.

[8] Expressão utilizada por LéviStrauss, em seu livro Totemismo hoje (Lisboa: Edições 70, 1986), para se contrapor a Malinowski. 
[9] Evans-Pritchard, E. E. Os Nuer [1940] São Paulo: Perspectiva, 1978.

[10] Sahlins, M. "O pessimismo sentimental e a experiência etnográfica". Mana. Estudos de Antropologia Social, vol. 3, 1997.

[11] Leach, E. R. "Dois ensaios a respeito da representação simbólica do tempo", in Repensando a antropologia. São Paulo: Perspectiva, 1974 , p. 193.

[12] Overing, J. "O mito como história: um problema de tempo, realidade e outras questões". Mana. Estudos de Antropologia Social, vol. 1, n. 1,1995 .

[13] Gell, Alfred. The anthropology of time. Cultural construction of temporal maps and images. Oxford/ Providence: Berg Oxford/Providence, 1992. Gell faz, inclusive, um apanhado sobre as noções de tempo encontradas nas obras de Durkheim, EvansPritchard, Lévi-Strauss e Leach.

[14] Destacamos, entre outras, as obras: Maine, Ancient law (1861); Bachofen, Das Mutterrecht (1861); Fustel de Coulanges, La cité antique (1864); McLennan's, Primitive marriage (1865); Tylor, Researches into the early history of mankind (1865), e Morgan, Ancient society (1877).

[15] Carneiro da Cunha, M. "Introdução a uma história indígena", in idem. (org.) História dos índios no Brasil. São Paulo: Companhia das Letras, 1992, p. 11.

[16] Varnhagen, F. A. de. História geral do Brasil [1854]. São Paulo: Melhoramentos, 1978, p. 30. entendendo e registrando a história em outras sociedades e - por que não? - na nossa. De pronto, lembro alguns exemplos: o tempo dos Nuer, que, como mostra Evans-Pritchard, adotavam um referencial interno9; o tempo dos Mendi, um povo que, como explica M. Sahlins, fazia tudo convergir para $\mathrm{si}^{10}$; o modelo pendular encontrado por Leach entre os Kachin, no qual o tempo é representado como uma repetição de inversões ${ }^{11}$; o tempo dos Piaroa, descrito por J. Overing, o qual é ora linear ora não ${ }^{12}$; o tempo dos Umeda, praticado no ritual pesquisado por Alfred Gell, quando se encenam com diferentes cores os vários ciclos da vida ${ }^{13}$, e o "nosso" - um tempo seriado e cumulativo. Aí estaria uma questão, de fato, antropológica: a busca de alteridades entre sociedades; formas diversas de expressão que ajudam a refletir, no limite, sobre a própria experiência.

Parece-me, ainda, importante reconhecer o papel que a história assumiu na própria constituição da antropologia como disciplina. Nesse sentido, a delimitação de fronteiras foi preocupação central de algumas escolas de antropologia, cujos autores buscaram definir seus modelos também partindo de uma contraposição de métodos. Essa "história" tem, assim, muitos trajetos: pretendo aqui realizar uma breve "antropologia da história".

\section{HISTÓRIA COMO CONJECTURA OU A AUSÊNCIA DA HISTÓRIA}

Por sinal, pode-se afirmar que, nos primórdios da produção antropológica - com o evolucionismo - incorporou-se a diacronia. É certo que essa antropologia de finais do século XIx procurava uma só história, pautando-se pela idéia de que certas culturas teriam permanecido na estaca zero da evolução, seriam fósseis vivos a testemunhar o passado da nossa própria sociedade. E, dessa forma, o modelo do Ocidente, caracterizado por uma evolução cumulativa e pela tecnologia - índice para definir o progresso obrigatório - , virava marca de uma humanidade unificada, mas cindida por desigualdades ${ }^{14}$. Foi nesse momento, também, que essas sociedades foram denominadas de "primitivas e da eterna infância"15. E, como tinham parado na história, não havia por que perguntar sobre ela. Conforme afirmava Varnhagen, o famoso historiador do Império brasileiro, "de tais povos na infância não há História: há só etnografia"16.

E foi por conta do modelo conjectural dessa escola que antropólogos culturalistas norte-americanos, de um lado, e funcionalistas ingleses, de outro, buscaram distanciar-se da diacronia e se opor à história. Condenava-se o evolucionismo não só porque sua reconstituição histórica não era verificável, mas também porque a história dessas sociedades parecia diminuta, perante o "presente etnográfico".

Para Franz Boas, por exemplo, era preciso localizar desenvolvimentos particulares; ou melhor, realizar uma análise comparativa limitada e processual. Aí estava o acento em culturas individuais; o 
recurso a uma história circunscrita ${ }^{17}$. Mas, por mais que Boas tenha advogado um "modelo diacrônico", não havia como encontrar história tomando como base a etnografia. Se a história representava um recurso ao tempo passado, definidor de realidades presentes, no domínio da etnologia - que lidava com sociedades sem escrita nenhum fato histórico parecia estar disponível. Confessava o antropólogo: "O material necessário para a reconstrução da História biológica da humanidade é insuficiente [...] o material para a reconstrução da cultura é ainda mais fragmentário [...] Dispomos de informações históricas apenas dos povos que dominaram a escrita" ${ }^{18}$.

Mas qual era a história que Boas procurava? Não seria uma história ocidental (pautada em registros escritos) e, por princípio, não encontrável nas culturas por ele estudadas? Segundo Lévi-Strauss, Boas manifestaria sua decepção ao renunciar à aspiração de entender "como as coisas chegaram a ser o que são", transformando-se num "agnóstico histórico completo"19. Como fazer história do presente sem recurso ao passado e sem transformar aquela história (ou sua suposta ausência) na "nossa história"? Estava em questão o encontro com outras histórias: as que não se recuperam via lápis e papel.

Mais radical era a posição de alguns antropólogos funcionalistas, que se privaram da diacronia, sob o pretexto de que a história que os etnólogos faziam não era boa o suficiente. Rompendo com a herança de Rivers, que defendeu um duplo "ponto de vista" na análise das sociedades - o estudo comparativo de diferentes estruturas sociais e o estudo histórico dos processos das sociedades humanas -, antropólogos sociais britânicos de gerações subseqüentes transformariam a concepção de dinâmica social (e de história) no pomo da discórdia. História lembrava os esquemas evolucionistas e a ideologia do progresso correntes no século XIX ${ }^{20}$. Além do mais, o próprio método implicava uma espécie de recusa à história, já que as sociedades humanas, sobretudo na visão de Radcliffe-Brown, eram entendidas como séries de sincronias (umas mais longas do que as outras) ${ }^{21}$. Por isso mesmo, o autor estabeleceria uma distância formal entre as disciplinas: ao etnógrafo destina-se o conhecimento direto, fruto da observação dos povos que estuda; já os historiadores se limitam aos arquivos escritos ${ }^{22}$. Assim, retomando o tema exclusivamente a partir de questões de método, Radcliffe-Brown desafiava: "Os antropólogos, que consideram o estudo histórico, instalam-se em conjecturas e pura imaginação" 23 .

A etnografia se convertia num modelo do presente, condicionado pela ausência de documentos escritos. E é mais uma vez Lévi-Strauss quem problematiza tal postura: "Pouca história vale mais do que nenhuma, dizer que uma sociedade funciona é truísmo, mas dizer que tudo nessa sociedade funciona é um absurdo" 24 . Afinal, o problema não era metodológico, e sim epistemológico: desconhecer que havia também história no presente, ou, ainda, que existiriam outras histórias e temporalidades inscritas na própria etnografia.
[17] Boas, F. "História e ciência em antropologia" [1936], in idem. Antropologia cultural (Rio de Janeiro: Zahar, 2004.

[18] Idem. "Os objetivos da pesquisa antropológica" [1932], in ibidem, p. 98. Para um apanhado das idéias de Boas, sugiro a leitura dos livros de Stocking Jr., G. W. (org.) Franz Boas. $A$ formação da antropologia americana. 1883-1911. Rio de Janeiro: Contraponto/Editora da UFRJ, 2004; e Moura, M. M. Nascimento da antropologia cultural. A obra de Franz Boas. São Paulo: Hucitec, 2004.

[19] Lévi-Strauss, C. "História e etnologia", in Antropologia estrutural, ed. cit., p. 21.

[20] Rivers, que praticou um método indutivo e de tradição empirista, introduziu em seu texto "História e etnologia" [1920] (in Cardoso de Oliveira, R. (org.) A antropologia de Rivers. Campinas: Editora da Unicamp, 1991), a idéia de "cronologia relativa", distinta de uma cronologia absoluta ou numérica. Vide também, para uma boa análise da obra de Rivers, Grimshaw, A. \& Hart, K. Anthropo$\log y$ and the crisis of the intellectuals. Cambridge: Prickly Pear Press, 1993.

[21] Mais recentemente, uma série de autores tem tecido críticas a essa perspectiva. Lembro, a título de exemplo, o trabalho de Clifford, James \& Marcus, George E. (eds.). Writing culture. Berkeley: University of California Press, 1986; e as críticas que fazem Grimshaw, Anna \& Hart, Keith (op. cit., p. 25), a esse tipo de etnografia, que, segundo eles "isolava as populações que estudava negando 
sua participação coletiva no movimento da história moderna".

[22] Radcliffe-Brown, A. R. Estrutura e função nas sociedades primitivas. Lisboa: Edições 70, 1989 , p. 11.

[23] Ibidem, p. 12.

[24] Lévi-Strauss, C. "História e etnologia", in Antropologia estrutural, ed. cit., p. 27.

[25] Vide "Marret Lectures". EvansPritchard, E. E. "Anthropology and history", in Essays in social anthropology. Londres: Faber and Faber, 1962; e Antropologia social, ed. cit., p. 100.

[26] Idem. "Anthropology and history", in ibidem, p. 48.

[27] Os tempos mais longos eram quase sempre estruturais; os tempos mais breves, ecológicos. O tempo estrutural era progressivo, enquanto o tempo ecológico era cíclico e delimitado.

[28] Evans-Pritchard, E. E. "Social anthropology: past and present", in Essays in social anthropology, ed. cit., p. 21.

[29] Ibidem, p. 56.

[30] Ibidem, p. 56; e Dumont, L. "For a sociology of India". Contributions to Indian Sociology, n. 1, 1957, p. 21.

[31] Evans-Pritchard, E. E. "Anthropology and history", in ibidem, p. 56; Dumont, L. ibidem, p. 63.

\section{OUTRAS HISTÓRIAS, TANTAS HISTÓRIAS}

Saída diferente encontraria Evans-Pritchard nas aulas que ministrou em 1950. Nomeando o debate entre antropologia e história como uma "querela doméstica", o autor refazia fronteiras e ao mesmo tempo as diluía. Caberia à antropologia o estudo de sociedades contemporâneas, mas não havia como ignorar a história. Dizia ele: "O conhecimento do passado leva a uma compreensão mais profunda da natureza da vida social no presente. A história não é mera sucessão de eventos, mas sim a relação entre eles; seu processo de desenvolvimento. O passado está contido no presente como este no futuro"25. O antropólogo introduzia, dessa maneira, uma outra chave explicativa: história é processo, e não há sociedade sem história, mesmo que no tempo sincrônico ${ }^{26}$.

E a preocupação não era nova. Já na década de 1940, EvansPritchard enfrentara a especificidade da categoria tempo em seu estudo sobre os Nuer, mostrando de que maneira esse conceito era condicionado pelo ambiente físico, mas suas respostas dependiam de estruturas sociais e suas relações internas ${ }^{27}$. Tratava-se de outra forma de nomear o tempo e de conceber a história: não a "nossa história" (ou a história do sujeito), mas uma história interna ao grupo e construída a partir de categorias nativas ${ }^{28}$.

Por sinal, em outro artigo, publicado em 1961, Evans-Pritchard relacionaria os impasses criados por uma antropologia que, de a-histórica, se tornara anti-histórica: o uso acrítico de fontes documentais, o pouco esforço em lidar com o passado, o suposto de que as populações nativas eram estáticas e, sobretudo, a idéia de que se podia desconhecer a mudança social. E insistia: "Não se chega à mudança sem o recurso à história, e, ignorando-a, estamos condenados a não conhecer o presente" ${ }^{29}$. Inteirado das discussões do momento, citava LéviStrauss e Louis Dumont para sintetizar seu ponto de vista: "História é o movimento pelo qual a sociedade se revela a si mesma e o que é"3o.

Evans-Pritchard acusava, assim, a existência de uma "ignorância da história". Contrário a essa posição, destacava as semelhanças entre as disciplinas - que teriam como objeto comum "traduzir idéias para outros termos e torná-las inteligíveis" - e tratava, ainda, de abolir dicotomias rígidas: o fato de os antropólogos estudarem pessoas em primeira mão, e os historiadores através de documentos, era apenas uma questão "técnica". Mas se esse problema parecia superado, restava lidar com outras faces da questão. Evans-Pritchard não só apontava para o interesse crescente entre antropólogos pela história, como apresentava dois níveis de análise: história seria o registro de eventos, mas também a representação deles ${ }^{31}$. E esse assunto parecia andar na ordem do dia.

Aliás, já em 1949 Lévi-Strauss lançara um ensaio sobre o tema: seu primeiro "Etnologia e história". Não era, porém, Evans-Pritchard que parecia em questão, mas o funcionalismo de Malinowski e Radcliffe- 
Brown ${ }^{32}$. "Pode-se indagar", sugeria ele, "se, privando-se de qualquer História, não teriam abandonado tudo" 33 .

Não é o caso de assumir a verve lévi-straussiana. Interessa mais mostrar como o etnólogo iniciava uma crítica epistemológica à maneira como a antropologia havia lidado com a temática. Como definiria em Raça e história: "Todas as sociedades humanas têm um passado da mesma ordem de grandeza [...] Não existem povos crianças, todos são adultos, mesmo aqueles que não tiveram diário de infância $e$ de adolescência"34. Mas, se não há povos sem história, existem, sim, variações nas formas como as sociedades se representam a partir da história. Trata-se de notar, portanto, diferentes "modelos" de conceber a história: uma progressiva e acumulativa; e outra igualmente ativa, que, no entanto, voltaria sempre a uma espécie de fluxo cíclico.

Essa é também a posição de Claude Lefort, que, em 1952, publicava As formas da história. Retomando o debate de Lévi-Strauss, Lefort carregava a herança do existencialismo e introduzia a noção de "historicidades". As culturas apresentariam formas distintas de devir, verificando-se variações entre uma história regida por um princípio de conservação e uma história que abre lugar para o novo; entre uma história visível - que faz ler a mudança - e uma história invisível - que apaga seus vestígios. Era por isso que o filósofo pensava em histórias no plural: "Há sociedades cuja forma se manteve durante milênios e que, a despeito dos acontecimentos de que foram teatro [...] ordenamse em função da recusa do histórico" ${ }^{35}$. Lefort denominava essas sociedades de "sem história" não porque desconhecessem mudanças, mas para evidenciar sua tendência a neutralizar os efeitos da mudança. Estamos, assim, diante de um outro patamar: "as sociedades estagnantes" não se situariam aquém da era do desenvolvimento histórico: elas elaborariam as próprias condições de sua estagnação ${ }^{36}$.

Diferentemente de Hegel, para quem a história nasce com o Estado, Lefort indagava sobre a vigência de sociedades que abriram mão da história; da nossa concepção de história. Por isso, a etnologia ajudaria a desvendar não formas primitivas da evolução humana, mas sim elementos de confronto entre tipos de devir: "uma mesma humanidade, às voltas com as mesmas questões, embora dando a elas soluções diferentes" 37 .

Mas voltemos ao texto de Lévi-Strauss, que ocupava lugar estratégico como introdução à coletânea Antropologia estrutura $\beta^{8}$. Nele, o autor anunciava a especificidade da etnologia que praticava e, por meio da história, repassava impasses da disciplina. Em suas palavras: "Pretender reconstituir um passado do qual seé impotente para atingir a História, ou querer fazer a História de um presente sem passado, drama da etnologia [ou do culturalismo] em um caso, da etnografia [ou do funcionalismo] em outro"39.

O ensaio começava, inclusive, descartando distinções que relegavam à história a alteridade no tempo e à antropologia no espaço:
[32] Radcliffe-Brown discordou dessa alcunha comum, que dizia ter sido inventada por Malinowski e só a ele devia se aplicar, pois diferiam radicalmente a começar pelo próprio conceito de função. Vide RadcliffeBrown, A. R., op. cit., p. 279.

[33] Lévi-Strauss, C. "História e etnologia”, in op. cit., pp. 25-7.

[34] Idem, Raça e história [1952]. São Paulo: Martins Fontes, 1975, p. 35.

[35] Lefort, C. "Sociedades 'sem história' e historicidade", in As formas da história. São Paulo: Brasiliense, 1979 , p. 17.

[36] Ibidem, pp. 17-8.

[37] Ibidem, pp. 55-6.

[38] O ensaio foi publicado originalmente na Revue de Metaphysique et de morale.

[39] Lévi-Strauss, C. Raça e história, ed. cit., p. 30. 
[40] Idem. "História e etnologia", in op. cit., p. 28 .

[41] Ibidem, p. 34. Nessa perspectiva a história estaria para a antropologia como a etnografia para a etnologia.

[42] Ibidem, p. 37.

[43] Ibidem, p. 41.

[44] Lévi-Strauss, C. \& Eribon, D. De perto e de longe. Rio de Janeiro: Nova Fronteira, 1990, p. 157.

[45] Lévi-Strauss, C. "Histoire et ethnologie". Annales E.S.C., vol. 38 , n. 6,1983, p. 1.218 .
"O comum é que são sistemas de representação que em seu conjunto diferem de seu investigador" ${ }^{\circ}$. Lévi-Strauss indica, ainda, variações nos procedimentos: enquanto o historiador se debruça sobre muitos documentos, o antropólogo observa apenas um. Entretanto, tal desproporção parece não incomodar o etnólogo, que ironizava a sua constatação dizendo que a saída seria "multiplicar os antropólogos", ou admitir que o próprio historiador recorre aos etnógrafos de sua época.

Dessa forma, a diferença não seria de objeto (a alteridade), muito menos de objetivo (o diverso), nem mesmo de método (menos ou mais documentos). No entanto, a paz era só alardeada, e uma nova dicotomia entraria em seu lugar: "Enquanto a História organiza seus dados em relação às expressões conscientes, a etnologia indaga sobre as relações inconscientes da vida social" ${ }^{41}$. A questão não era, porém, técnica ou metodológica, já que, com tal distinção, Lévi-Strauss pretendia, mais que desautorizar a produção historiográfica, anunciar as bases de uma antropologia estrutural. Tendo como objetivo chegar às estruturas inconscientes, o etnólogo explicava: "Na lingüística e na etnologia não é a comparação que fundamenta a generalização, mas sim o contrário" 42 .

A divisão entre presença ou ausência de documentos parece, assim, não ser falsa, mas pouco essencial. E o artigo terminava com um estranho happy end, depois de ter demarcado distinções tão fortes. "Elas nada podem uma sem a outra" ${ }^{3}$, diria o etnólogo. E eu acrescentaria: uma a história - sem a outra - a antropologia. Afinal, Lévi-Strauss escolhera a lingüística como sua noiva e largava a história no altar.

Quarenta anos depois, o mestre francês ainda procuraria defender seu ensaio dos ataques de historiadores: "Meu artigo tendia a mostrar que uma oposição nefasta e caduca deveria ceder lugar aos trabalhos que os etnólogos e historiadores hoje podem realizar lado a lado" 44 . Lévi-Strauss trataria, inclusive, de esclarecer seu partido em novo artigo, apresentado em 1983, por ocasião do V Ciclo de Conferências em homenagem a Marc Bloch. Apesar da repetição do título "História e etnologia" - , não existem referências explícitas ao texto anterior, e, nesse caso, o ensaio principiava com um elogio (breve) à obra de Bloch. Seu objetivo era examinar as "estreitas relações entre as disciplinas" e adiantar que "graças à antropologia [...] os historiadores teriam percebido a importância das manifestações obscuras". E é por meio dessas "manifestações" que o autor introduz um novo campo: uma "antropologia histórica". O problema é então anunciado da seguinte maneira: "Todas as sociedades são históricas, mas apenas algumas o admitem francamente, outras preferem ignorá-lo" 45 . As culturas não seriam classificadas por uma escala ideal, ou em nome de seu grau de historicidade, mas pela maneira como o pensamento coletivo se abre à história: como e quando a vêem como ameaça ou quando percebem nela um instrumento para transformar o presente. 
Há assim uma decorrência no argumento que gostaria de acompanhar: se tomarmos o tempo como categoria analítica, não há sociedade que não seja histórica. Ou melhor, ficam evidentes as diferenças entre um "tempo estrutural" - como categoria de análise - e um "tempo histórico", que é antes uma forma circunscrita, datada e culturalmente condicionada de conceber a passagem do tempo. $O$ ensaio revela, também, que optar pela estrutura não significa recusar a história e, com esse intuito, explora o conceito de casa. Ao analisar o casamento de primos em sociedades de épocas e lugares diferentes, demonstra como as culturas esquentam e esfriam, abrem-se e fecham-se à história. Não é o caso de explorar tal concepção, mas sobretudo de mostrar como, segundo o autor, abria-se para a história o campo das "estruturas profundas", porque comuns ao passado. E ele ponderava: "Como é pouco plausível que as sociedades humanas se repartam em dois grupos irredutíveis, alguns revelando a estrutura, outros o acontecimento, duvidar que a análise estrutural se aplique a algumas conduz a recusá-la para todas" 46 .

E a história estaria presente em vários textos de Lévi-Strauss ${ }^{47}$. Neles, o autor lança mão da etnologia, com o objetivo de elaborar uma crítica ao papel universalizante da história ocidental. Por sinal, se até agora trabalhamos com duas categorias - a história dos historiadores (como a denominam Gaboriau e Goldman) ${ }^{48}$ e a história como conceito analítico -, é preciso lembrar a crítica que o etnólogo fará à "Filosofia da História". E foi com o intuito de se contrapor a algum sentido privilegiado da história, definidor da própria humanidade, que escreveu o último capítulo d'O pensamento selvagem. O objetivo era acusar a leitura sartriana da história, que tomou a dialética como modelo geral e invocou o critério da universalidade da consciência histórica. Afirmava Lévi-Strauss: "É preciso bastante egocentrismo e ingenuidade para crer que o homem está todo inteiro, refugiado em um só dos modos históricos de seu ser [...] A História não é, pois, a História, mas a História para" 49 . Toda história é, portanto, seleção, e nossa própria versão ocidental seria redutível a um código: a cronologia, nossa cosmologia particular.

Assim, apoiando-se num tema aparentemente pouco relevante em sua teoria, Lévi-Strauss chega a conclusões centrais nesse debate: as formas de nomear a historicidade ${ }^{50}$. E a antropologia - por meio da comparação e do estranhamento - ocuparia lugar privilegiado, revelando como existem tantas histórias como culturas, religiões e parentescos. A distinção entre "histórias frias e quentes" é, dessa maneira, apenas um modelo para chegar à alteridade: "Ela não postula uma diferença de natureza [...] Refere-se às atitudes subjetivas que as sociedades adotam frente à História" ${ }^{51}$.

Lévi-Strauss trabalharia, ainda, com outro conceito aproximado de história: a noção de "grupo de transformações" 52 . Esse tipo de proposta já está presente no primeiro volume das Mitológicas, quando o
[46] Ibidem, p. 1.229 .

[47] Em obras como "História e etnologia" (1949); Raça e história (1952); Aula inaugural (1960); os dois últimos capítulos de $O$ pensamento selvagem (1962); o segundo "História e etnologia" (1983); “Um outro olhar" (publicado na revista L'Homme em 1983); História de lince (1991); "Voltas ao passado" (entrevista para a revista Mana de 1998), e nas Mitológicas (1964-71).

[48] Gaboriau, M., op. cit., e Goldman, M., "Lévi-Strauss e os sentidos da história", ed. cit.; "LéviStrauss e os sentidos da história", in idem, Alguma antropologia ed. cit.

[49] Lévi-Strauss, C. "História e dialética", in $O$ pensamento selvagem. São Paulo: Companhia Editora Nacional, 1976, p. 292

50] Vide também, nesse sentido, artigo de Goldman, M. "LéviStrauss e os sentidos da história", in ed. cit.

[51] Lévi-Strauss, C. "Voltas ao passado". Mana. Estudos de Antropologia Social, vol. 4, n. 2, 1998 , p. 108.

[52] Idem. "A estrutura dos mitos", in Antropologia estrutural, ed. cit., p. 258 . 
[53] Idem. O cru e o cozido. São Paulo: CosacNaify, 2004, pp. 20-1.

[54] Pateo, R. D. do. "Claude LéviStrauss: estrutura, história e transformação". Tradução de Beatriz Perrone-Moisés, 2004, p. 8 (mimeo).

[55] Lévi-Strauss, Claude. "A harmonia das esferas", in Do mel às cinzas, 2003, pp. 401-8 (mimeo).

[56] Vide, nesse sentido, artigo de Almeida, M. "Simetria e entropia: sobre a noção de estrutura em LéviStrauss", Revista de Antropologia, vol. 42, n. 1-2, 1998.

[57] Vide, nesse sentido, Delacampagne, C. \& Traimond, B. "A polêmica Sartre/Lévi-Strauss revisitada. Nas raízes das ciências sociais de hoje", Les Temps Modernes, n. 596, nov.-dez., s/d.

[58] Sahlins, M. Historical metaphors and mythical realities. Michigan: Michigan Press, 1986, p. 9. autor esclarece ter configurado "o grupo de transformações de cada seqüência, seja no interior do próprio mito, seja elucidando as relações de isomorfismo entre seqüências extraídas de vários mitos provenientes da mesma população" 53 . Ao ancorar suas análises em sociedades concretas, o etnólogo mostrou como, para o estruturalismo, as transformações históricas concretizam-se por meio de inversões lógicas, segundo as quais os elementos contidos na experiência do mundo concreto são a todo momento reelaborados, tendo como base princípios estruturantes comuns a toda a humanidade ${ }^{54}$. Na sua definição: “[...] a análise estrutural não recusa a história. Ao contrário, concede-lhe um lugar de destaque [...] Para ser viável, uma investigação voltada para as estruturas começa por curvar-se diante do poder e da inanidade do evento" 55 .

\section{UMA ANTROPOLOGIA DAS HISTORICIDADES E SEUS VÁRIOS CAMINHOS}

Não é hora de aprofundar esse debate, que implicaria pensar no conceito de "entropia", e como, para Lévi-Strauss, as estruturas não seguem um sentido lógico que pressuponha a mudança visível: elas podem não se alterar, se perder, morrer, e assim por diante $e^{56}$. De toda maneira, o que se quer destacar é como, por meio da questão da história, Lévi-Strauss revela-se um teórico da diversidade; constatação que ajuda a nuançar interpretações enganosas acerca dessa obra. Afinal, desde os anos 1970, vários antropólogos dividiram-se entre aqueles que se opunham ao modelo estrutural, em sua suposta condenação à história ${ }^{57}$, e aqueles que se declaravam abertamente influenciados por ela. Não pretendo listar os nomes que tomaram parte nesse debate. Julgo mais proveitoso examinar, em função de seu destaque no campo antropológico, o papel de Marshall Sahlins, que vem se definindo como um "estruturalista histórico".

Além do mais, Sahlins tem priorizado, em vários estudos, questões semelhantes às que temos tratado aqui: o modo como as culturas carregam suas próprias historicidades. Aí estaria o projeto intelectual mais amplo desse autor, implicado na tentativa de elucidar de que forma a infra-estrutura econômica é ela própria organizada pelos diferentes esquemas culturais. Significa dizer, entre outras coisas, que o sistema mundial, para além do processo de globalização, estaria sendo relido, a todo momento, por categorias locais.

Foi, porém, no livro Historical metaphors and mythical realities que Sahlins se imiscuiu mais diretamente no debate entre antropologia e história. Como explicava o autor: "O grande desafio para uma História antropológica não é só saber como os eventos são ordenados pela cultura, mas como, nesse processo, a cultura é reordenada. Como a reprodução de uma estrutura carrega a sua própria transformação" ${ }^{8}$. $\mathrm{O}$ objetivo era demonstrar de que maneira qualquer recepção se pauta sempre por estruturas anteriores, motivadas pela dinâmica da cultura: 
"O processo histórico caminha num movimento recíproco entre a prática da estrutura e a estrutura da prática" 59.

É esse processo que Sahlins denomina, em Ilhas de história ${ }^{60}$, de "a reavaliação funcional de categorias". O autor introduzirá estrutura na história (só que a partir do modelo de $\operatorname{Hocart}^{61}$ ), mostrando como, mesmo na representação mais abstrata dos signos - a cosmologia - a estrutura está em movimento. O problema levaria menos a explodir o conceito de história pela experiência antropológica da cultura, e mais a apresentar a experiência histórica, incluindo a estrutura. Por sua vez, a cultura assim equacionada corresponde à organização da situação atual em termos do passado. É isso que o autor chama de "estrutura da conjuntura": a forma como as culturas reagem a um evento, fazendo o contexto imediato dialogar com estruturas anteriores. A história é construída tanto no interior de uma sociedade como entre sociedades que repõem estruturas passadas na orquestração do presente.

É também nessa perspectiva que Sahlins analisa a incorporação do capitalismo em países periféricos. "Cada cultura é (no limite) um sistema mundial", declararia em entrevista recente ${ }^{62}$, mostrando como é preciso dar ouvidos aos "povos periféricos", na melhor tradição antropológica, que sempre se definiu como "uma ciência social do observado: seja porque ela visa atingir em sua descrição as sociedades estranhas [...] seja porque ela amplia seu objeto até incluir nele a sociedade do observador" ${ }^{63}$. Nem tão distantes estariam, portanto, Lévi-Strauss e Sahlins, sobretudo quando buscam chegar a temporalidades diferentes.

A obra de Sahlins sinaliza ainda, para outros rumos da disciplina, que, ao se concentrar no tema do poder, destaca como atentar para estruturas e permanências, o que não significa recusar a história e a mudança. Seus livros revelam, por outro lado, como a prática política carrega dimensões simbólicas e rituais que não se limitam ao estudo da lógica política mais tradicional. Aí estaria, em minha opinião, a novidade dos trabalhos desse autor, que tem explorado o rendimento da análise estrutural para pensar em outras histórias contingentes: as releituras de culturas, assim chamadas, periféricas.

Sob essa ótica podemos aproximar, também, a excursão histórica que Clifford Geertz realiza em Negara ${ }^{64}$. A partir do estudo de uma prática ritual da Indonésia, o autor não só elabora uma crítica à filosofia política ocidental, como defende uma concepção específica de história: "A História de uma civilização", explica ele, "pode ser descrita como uma série de grandes eventos [...] ou então enquanto fases de desenvolvimento sociocultural" ${ }^{65}$. Geertz reconhece a complementaridade das abordagens, e acrescenta uma terceira: a etnográfica. Não se trata de acreditar que "a ilha tenha sido poupada à História" ${ }^{66}$, ou que os costumes do presente sejam prova de existência no passado. A idéia é reafirmar que há história no "presente etnográfico".

Além do mais, por meio da análise das dimensões simbólicas do
[59] Ibidem, p. 72.

[6o] Idem. Ilhas de história [1987]. Rio de Janeiro: Zahar, 1990.

[61] Vide, por exemplo, Hocart, A. M. Kinship [1927]. Oxford: Oxford University Press, 1969.

[62] Entrevista para o livro Antropologias: histórias e experiências, organizado por Fernanda Peixoto, Heloisa Pontes e Lilia Moritz Schwarcz (Belo Horizonte: Editora da UFMG, 2004).

[63] Lévi-Strauss, C. "Lugar da antropologia nas ciências sociais e problemas colocados por seu ensino" [1954], in Antropologia estrutural, ed. cit.

[64] Geertz, C. Negara. O Estado teatro no século XIX [1980]. Lisboa: Difel, s/d.

[65] Ibidem, p. 15 .

[66] Ibidem, p. 18. 
[67] Ibidem, p. 169.

[68] O antropólogo focaliza a narrativa na ação carismática de dois líderes - Sunan Kalidjaga e Ali al-Hassan - com o intuito de explicar por que eles teriam institucionalizado diferentes formas de islamismo.

[69] Geertz, C. Islam observed. Religious development in Morocco and Indonesia. Chicago: Chicago University Press, 1971, pp. 59-6o.

[70] Vide, nesse sentido, Sahlins, Marshall. "Cosmologias do capitalismo", Religião e Sociedade, n. 16, 1992.

[71] Fox, R. \& Gingrich, Andre Anthropology, by comparison. Londres/Nova York: Routledge, 2002.

[72] Vide Obeyesekere, G. The apotheosis of Captain Cook. Princeton: Princeton University Press/Bishop Museum Press, 1992; Bhabha, Homi K. O local da cultura. Belo Horizonte: Editora da UFMG, 1998; Sahlins, M. Como pensam os nativos. São Paulo: Edusp, 2001; e idem. Esperando Foucault, ainda. São Paulo: CosacNaify, 2004 .

[73] Vide, nesse sentido, Fox, R. \& Gingrich, A., op. cit., p. 167.

[74] Vide, entre outros, Isaac, Rhys. Transformations of Virginia. Chapel Hill: University of North Carolina Press, 1982; Clendinnen, I. Ambivalent conquests: Maya and Spaniard in Yucatan, 1517-1570. Cambridge: Cambridge University Press, 1987; e Dening, Greg. Islands and beaches. Discourses on a silent land. 17741880. Melbourne: Melbourne University Press, 1980.

[75] Vide, nesse sentido, Pompa, C. Religião como tradução. São Paulo: Edusc/Anpocs, 2003; e Ginzburg, C. "Introdução", in $O$ queijo e os vermes. São Paulo: Companhia das Letras, 1999.

[76] Vide, nesse sentido, entre outros, poder estatal, Geertz destacou exemplos alternativos à versão ocidental de Estado, assim como relativizou nossa concepção de poder, herdeira da moderna teoria política do século Xvi ${ }^{67}$. Em Negara apresentava, portanto, formas distintas de política, poder e história, reconhecidas por um método tão original quanto contestado: o "doing history backwards". E esse método já havia sido experimentado em Observando o islã, quando Geertz comparou a fé religiosa no Marrocos e na Indonésia ${ }^{68}$. Sem entrar no argumento da obra, vale atentar para o tipo de história preconizada: "Em certo sentido, formular o problema nesses termos é fazer uma História de frente para trás [...] A vida, como disse Kierkegaard, se vive para a frente, mas se compreende para trás" ${ }^{69}$.

A partir desse ângulo delimitado, as obras de Geertz retomariam problemáticas dos textos de Sahlins: ambos analisam de que modo processos do presente são determinados por estruturas do passado, mas geram experiências inusitadas. No entanto, existem também dissonâncias: diferentemente de Geertz, Sahlins define uma espécie de vocação para as sociedades que estuda ${ }^{70}$, acreditando que as culturas preexistentes limitam de forma radical as possibilidades de mudança ${ }^{71}$. Por outro lado, percebem-se divergências na maneira como Sahlins entende as culturas periféricas: tal qual centros da transformação histórica. Aliás, esse seria o cerne da crítica de autores como Bhabha e Obeyesekere, que acusaram uma tendência culturalista nas obras de Sahlins ${ }^{72}$.

Se não há tempo para refazer esse debate (que implicaria adentrar a leitura pós-moderna), o que se pode dizer é que há uma antropologia interessada na transformação histórica; ou melhor, nas manifestações divergentes de processos históricos assemelhados ${ }^{73}$.

O fato é que esses autores, entre outros ${ }^{74}$, têm investido numa antropologia histórica atenta às reelaborações locais. $\mathrm{O}$ suposto é que do contato entre culturas ambas saiam alteradas, não resultando apenas dois blocos: um impondo esquemas culturais e outro absorvendo; um sendo destruído e outro mantendo sua tradição imutável ${ }^{75}$.

Lembro que tal perspectiva pode ser acompanhada também no contexto da América indígena. Uma clara revisão tem demonstrado, entre outros temas, como não basta dar aos povos nativos ora o papel de heróis que lutam pela conservação de sua cultura - entendida como essência imutável — ora o de vítimas passivas ${ }^{76}$. Além do mais, no lugar da noção de culturas "puras", ou conspurcadas pelo encontro, vários trabalhos insistem atualmente nas estratégias de negociação e de reformulação de identidades: na fronteira. Sem incorrer no erro de supor que os contatos culturais se travam de modo harmonioso e igualitário, trata-se de investigar como elementos externos foram relidos pelas culturas locais, não só porque revelavam imposição política, mas, também, porque faziam sentido em determinado contexto, em si significativo ${ }^{77}$. 
Nesse sentido, uma série de pesquisas antropológicas vem reconsiderando as maneiras de fazer essa "história do encontro" e criticando a representação do nativo como um "elemento passivo" de sua história. De um lado, há toda uma produção atenta às lógicas políticas e culturais desses contatos, e que tem a sociedade ocidental como referência de análise $e^{78}$. De outro, um conjunto de trabalhos busca não uma história (ocidental) dos índios brasileiros, mas uma história indígena em seus próprios termos ${ }^{79}$. Trata-se de uma linha que, em vez de acreditar que o discurso sobre os povos de tradição não européia serve para iluminar nossas "representações do outro", passa a indagar de que forma os "outros representam os seus outros" 80 . A alternativa inaugura um construtivismo de mão dupla, no qual a antropologia reconhece que suas teorias sempre exprimiram um compromisso, em contínua negociação histórica, entre os mundos do observado e do observador, e que toda antropologia bem-feita será sempre uma "antropologia simétrica", nos termos de Latour ${ }^{81}$.

Não se trata de repassar a produção etno-histórica ou de esgotar autores e obras. Vale a pena assinalar, porém, que o que está em pauta é reconsiderar formas indígenas de pensar e fazer história - um regime de historicidades próprio - , uma outra história, para voltarmos a nosso debate central. Mas é necessário fazer uma parada estratégica. Não pretendi construir uma espécie de patchwork de teorias, nem imaginar que todos "viveram felizes para sempre". Também não foi minha intenção chegar a uma visão consensual, mesmo porque outros trabalhos poderiam ser aqui incluídos. O que fiz foi, através da questão da história, buscar articular perspectivas, se não afinadas, ao menos convergentes. É por meio da comparação e do estranhamento que se chega a outras histórias, paralelas à nossa própria experiência. E não estamos longe da definição de Merleau-Ponty, que viu na antropologia "a maneira de pensar quando o objeto é outro e exige a nossa própria transformação" 82 .

\section{TEMPORALIDADES EM NOSSA HISTÓRIA OCIDENTAL}

E é mais uma vez Lévi-Strauss quem mostra como "nas nossas sociedades a história substitui a mitologia e desempenha a mesma função". Para as sociedades sem escrita, a mitologia asseguraria que o futuro permanece fiel ao presente e ao passado; já para nós, a história garantiria que o futuro será sempre distinto do presente ${ }^{83}$.

Assim, a autoconsciência histórica faz parte de culturas que trazem para dentro de si tal movimento progressivo, o que faria da nossa sociedade, uma "sociedade a favor da história". Mas o perigo de apostar nessa visão unitária é caricaturar a nós mesmos. Se outras sociedades carregam "histórias no plural", também o Ocidente não é só (e sempre) um conjunto de sociedades que se pauta pela cronologia.

E não foram poucos os historiadores que se voltaram sobre "nossos" tempos. Marc Bloch, em Os reis taumaturgos ${ }^{84}$, ao fazer uma
Pompa, C., op. cit.; Sider, G. "Identity as history: ethnohistory, ethnogenesis and ethnocide in the Southeastern United States", Identities, vol. 1, n. 1, 1994, pp. 109-22; e Stern, Steven. "Paradigms of conquest: history, historiography and politics", Journal of Latin American Studies, vol. 24, 1992, pp. 1-34.

[77] Vide, na produção historiográfica, Gruzinski, S. La colonisation de l'imaginaire. Paris: Gallimard, 1988; idem. La pensée métisse. Paris: Fayard, 1999; Vainfas, R. A heresia dos índios. Catolicismo e rebeldia no Brasil colonial. São Paulo: Companhia das Letras, 1995; e Puntoni, P. A guerra dos bárbaros. Povos indígenas e colonização do sertão. Nordeste do Brasil, 1650-1720. São Paulo: Hucitec/Edusp, 2002. Para o uso do conceito de negociação, destaco os trabalhos de Reis, J. J. Escravidão e invenção da liberdade: estudos sobre o negro no Brasil. São Paulo/Rio de Janeiro: Brasiliense/ CNPq, 1988); e de Silva, Eduardo. Negociação e conflito: a resistência negra no Brasil escravista. São Paulo: Companhia das Letras, 2000.

[78] Oliveira, J. P. de. Ensaios em antropologia histórica. Rio de Janeiro: Editora da UFRJ, 1999; Lima, A. C. "A identificação como categoria histórica", in Oliveira, J. P. (org.). Os poderes e as terras dos índios. Comunicações 14, Rio de Janeiro: PPGAS/Museu Nacional/UFRJ, 1989; Monteiro, John. Tupis, Tapuias e historiadores. Estudos de história indígena e do indigenismo. Campinas: Tese de livre-docência, Unicamp, 2001; Wright, Robin (org.). Transformando os deuses. Os múltiplos sentidos da conversão entre os índios do Brasil. Campinas: Unicamp, 1999.

[79] Cunha, M. C. da (org.), op. cit.; Cunha, M. C. da \& Castro, Eduardo Viveiros de. "Vingança e temporalidade: os Tupinambás", Anuário Antropológico, vol. 85, 1986, pp. 57-78; Albert, B. \& Ramos, A. (orgs.). Pacificando o branco. Cosmologias do contato no Norte Amazônico. São Paulo: Unesp, 2002; Franchetto, B. \& Heckenberger, M. (orgs.). Os povos do Alto Xingu. História e cultura. Rio de Janeiro: Editora da UFRJ, 2001; Amoroso, M. "Conquista do paladar: os Kaingang e os Guarani para além das cidadelas cristãs", Anuário Antropológico. Brasília: UnB, 2004; 
Perrone-Moisés, B. “Aldeados, aliados, inimigos e escravos: lugares dos índios na legislação portuguesa para o Brasil", Actas do Congresso Internacional Portugal-Brasil: Memórias e Imaginários, v.1., Lisboa: GTMECDP, 2000. pp.147-64; Gallois, D. Mairi revisitada: a reintegração da fortaleza de Macapá na tradição oral dos Waiãpi. São Paulo: Núcleo de História Indígena e do Indigenismo (NHII-USP)/FAPESP, 1994; idem. Sociedades indígenas e suas fronteiras na região sudeste das Guianas, 2004 (mimeo); Comaroff, J. Body and power. Spirit of resistence: the culture and history of a South African people. Chicago: Chicago University Press, 1985; idem. Ethnography and the historical imagination. Boulder: Westview Press, 1992; idem, Comaroff, J. \& Farage, N. As muralhas do sertão: os povos indígenas no rio Branco e a colonização. Rio de Janeiro: Paz e Terra, 1991.

[8o] Castro, E. V. de. "Etnologia brasileira”, in Miceli, S. (org.). O que ler na ciência social brasileira (19701995). 1. Antropologia. São Paulo: Editora Sumaré, 1999, p. 155.

[81] Ibidem, p. 156. Latour, B. Jamais fomos modernos. São Paulo: Editora $34,1994$.

[82] Merleau-Ponty, M. "De Mauss a Claude Lévi-Strauss", in MerleauPonty. São Paulo: Abril Cultural, 1984 (col. Os pensadores), pp. 199-200.

[83] Lévi-Strauss, C. Mito e significado. Lisboa: Edições 70, 1979, pp. 63-4.

[84] Bloch, M. Os reis taumaturgos [1924]. São Paulo: Companhia das Letras, 1993.

[85] Braudel, F. O Mediterrâneo e o mundo mediterrânico na época de Filipe II [1949]. Lisboa: Publicações D. Quixote, 1995 , p. 15 ; idem. "História e ciências sociais. A longa duração", in Escritos sobre a história. São Paulo: Perspectiva, 1978.

[86] Darnton, R. O grande massacre de gatos. Rio de Janeiro: Graal, 1986. Carl Schorske, uma grande influência na obra de Darnton, em Viena finde-siècle (São Paulo: Companhia das Letras, 1988, p. 17), revela como no trabalho do historiador se cruzam "duas linhas. Uma vertical ou diacrônica, com a qual ele estabelece a relação de um texto ou um sistema de pensamento com expres- espécie de "história do milagre", inaugurava uma antropologia histórica, atenta aos elementos culturais persistentes, quase estruturais. Anos depois, Fernand Braudel, em O Mediterrâneo, indicava como encontrara um mundo marcado por temporalidades distintas. Permanências e regularidades da história mediterrânea mostravam a importância da "longa duração" 85 .

Mais recentemente, Robert Darnton, em O grande massacre de gatos, recuperaria esse diálogo, analisando um ritual ocorrido numa gráfica parisiense, no final da década de 1730, onde conviviam vários tempos: 0 tempo da Revolução, o tempo dos rituais, mas também o tempo longo da feitiçaria ${ }^{86}$. Carlo Ginzburg, em História noturna, ao buscar no sabá exemplos profundos de "formações culturais de compromisso", elegeu o modelo estrutural. Se o objetivo era retomar o ritual dando lugar ao observado, já a metodologia insistiu numa análise sincrônica ${ }^{87}$.

Mas, uma vez que não há espaço aqui para recuperar esse debate na historiografia - e perguntar quais foram as antropologias que a história encontrou ${ }^{88}$-, gostaria de finalizar trazendo a discussão "para o meu campo". É possível reverter o eixo de análise e, por meio da alteridade, refletir não só sobre os "outros", mas acerca da nossa própria cultura e suas tantas historicidades. Por esse caminho assumiríamos uma postura diferente diante das "sociedades complexas", que implica, como diz Viveiros de Castro, "antropologizar o centro e não apenas a periferia da nossa cultura" 89 .

É preciso questionar esse "ar de novidade" sem perder, porém, a oportunidade de provocar. Se não são poucos os trabalhos de antropólogos brasileiros que têm se utilizado da diacronia como forma de reflexão ${ }^{90}$ - e basta lembrar a herança de Gilberto Freyre ${ }^{91}$ - é hora de mostrar como esse tipo de abordagem teórica tem influenciado meu trabalho, em particular. Fazendo um paralelo com minhas pesquisas, diria que tratei de enfrentar conceitos nativos mediante o recurso à história. Inspirada por alguns dos autores citados, estudei instituições científicas do século xix e retomei noções - como raça e cidadania. Tal pesquisa implicou "historicizar" categorias, ou, nos termos de Sahlins, encontrar novas formas para velhas estruturas. A idéia foi privilegiar a versão local, o que levou a pensar na "originalidade da cópia" e como a raça fazia aqui as vezes da nação ${ }^{92}$.

Também nessa linha analisei a representação da monarquia, durante o Segundo Reinado brasileiro, procurando refletir sobre a dimensão simbólica do poder político e das tantas realezas aqui relidas, em historicidades variadas: o tempo curto da política das elites, o tempo longo do rei das festas e do monarca que sobrevive na memória como mito ${ }^{93}$.

Acredito ainda que uma antropologia histórica das "sociedades complexas" deve transpor não "termos", mas "relações" e "conceitos" 94 , e o recurso à história pode representar uma abordagem privilegiada. É nessa direção que vem se desenvolvendo minha pesquisa atual, que trata 
do pintor Nicolas Taunay, o qual, chegado ao Brasil em 1816, tinha a complicada tarefa de "traduzir" para as telas a realidade local. O artista lamentava que as cores do Brasil não encontravam nenhum referencial neoclássico e, acima de tudo, que o tempo dos trópicos insistia em não se deixar captar: "Como prender o sol dos trópicos, que rouba o tempo e insiste em correr?", indagava o pintor. Aí estava outro tempo: o tempo ao sul do equador, o tempo da viagem e da situação passageira. O tempo da Revolução, que perpetua na tela as virtudes do governante, não cabe na pintura de Taunay, que fez questão de expor um certo mal-estar entre modelo e realidade: de um lado a tentativa de engrandecer a corte exilada; de outro o esforço de obscurecer a escravidão.

Durante os quase cinco anos em que permaneceu no Brasil, Taunay produziu 45 obras, mas apenas quinze sobre essa natureza que resistia a uma leitura fácil: os trópicos não combinavam com o rigor neoclássico, assim como as figuras não se pareciam com as da Arcádia ou da Antigüidade. Exemplo do tempo distinto dos trópicos é encontrado na tela Cascatinha da Tijuca, na qual o pintor surge diminuto perante a natureza que tenta capturar. "Pintei o quadro", admitiu ele, "antes que o tempo me enganasse." Taunay retrata, mas também contempla: interioriza a experiência e expõe o conflito entre o homem e a natureza. Nesse processo, a natureza entra no lugar da história e representa a nação. Era a realeza da natureza que acolhia os Bragança; uma paisagem edenizada que constituía a nacionalidade.

Mas é em outra tela - Gato com papagaio - que a reflexão sobre o tempo aparece de maneira mais direta. Nela estão dispostos alegoricamente dois animais que revelam, respectivamente, o mais tradicional e o mais exótico, a longa e a curta duração. Animal de representação clássica, o gato, como objeto de simbolização, tem sido associado à metonímia sexual, à feitiçaria e à traição. Com efeito, ele lembra tudo o que é passado, mas, como alegoria, representa a falsidade. Falta falar do papagaio, que estaria presente já nas primeiras imagens da América. Ademais, como alegoria, os pássaros, além de aparecerem com freqüência na mão do Cristo infante, representam a "alma". No entanto, se não ficarmos restritos a uma análise formal, poderemos notar como os dois animais pouco se olham. Parecem observar, de soslaio, o pintor, que também os observa. Aqui estão a lealdade e a falsidade, o novo e o velho, o tempo imediato e o mais longo. Estando dispostos lado a lado, pouco se comunicam, tal qual um grande (e forçado) convívio entre tempos distintos. Como diz Ginzburg, "expulsa silenciosamente pela porta, torna (a história) a entrar pela janela"95.

\section{O TEMPO DA MONTANHA}

O desafio é enfrentar, portanto, as várias histórias da nossa cosmologia, tema retomado por Latour para pensar "os modernos": sões anteriores no mesmo ramo de atividade cultural. A outra é horizontal, ou sincrônica; com ela o historiador avalia a relação do conteúdo do objeto intelectual com as outras coisas que vêm surgindo, simultaneamente, em outros ramos da cultura".

[87] Ginzburg, C. História noturna. Decifrando o sabá. São Paulo: Companhia das Letras, 1991. Lembro do exemplo dado por J. S. Martins, no texto "A ferrovia e a modernidade em São Paulo", Revista USP, n. 63 , set.-nov. 2004, p. 10, que, citando R. Kipling na viagem que fez pela São Paulo Railway, destacava como a economia de tempo dos novos trens, contrastava com a demorada dedicação dos passageiros às despedidas; "indício de cultura aristocrática de quem tem tempo para os rituais da sociabilidade".

[88] Não há espaço para recuperar todos os trabalhos que enfrentaram, na historiografia, a temporalidade. Cito só alguns, que, na escola francesa, realizaram esse debate mais diretamente: Le Goff, J. La naissance du purgatoire. Paris: Gallimard, 1981 e L'imaginaire medieval. Paris: Gallimard, 1985; Duby, G. Le temps des cathèdrales. Paris: Gallimard, 1976 e Les trois ordres ou l'imaginaire feodale. Paris: Gallimard, 1978; Dumézil, G. Heurs et malheurs du guerrier. Paris: Flammarion, 1985, e Le Roy Ladurie, E. Montaillou. Povoado occitânico de 1294-1324. São Paulo: Companhia das Letras, 1997. Sugiro também a leitura do livro organizado por Pallares-Burke, M. L. G. As muitas faces da história. São Paulo: Unesp, 2000, que reúne entrevistas com nove historiadores europeus e norte-americanos. Nelas o debate entre antropologia e história é retomado em vários momentos.

[89] "Entrevista com o antropólogo Eduardo Viveiros de Castro", Sexta Feira: Antropologia, Artes e Humanidades, Corpo, n. 4, 1999, p. 117. Para um exemplo desse tipo de postura, que dialoga com "conceitos centrais", cito o trabalho de Grin Debert, G. A reinvenção da velhice. São Paulo: EDUSP, 1999, em que a autora demonstra como, mesmo nas sociedades ocidentais, a idade cronológica é estabelecida por um aparato cultural independente e neutro em relação à estrutura biológica. 


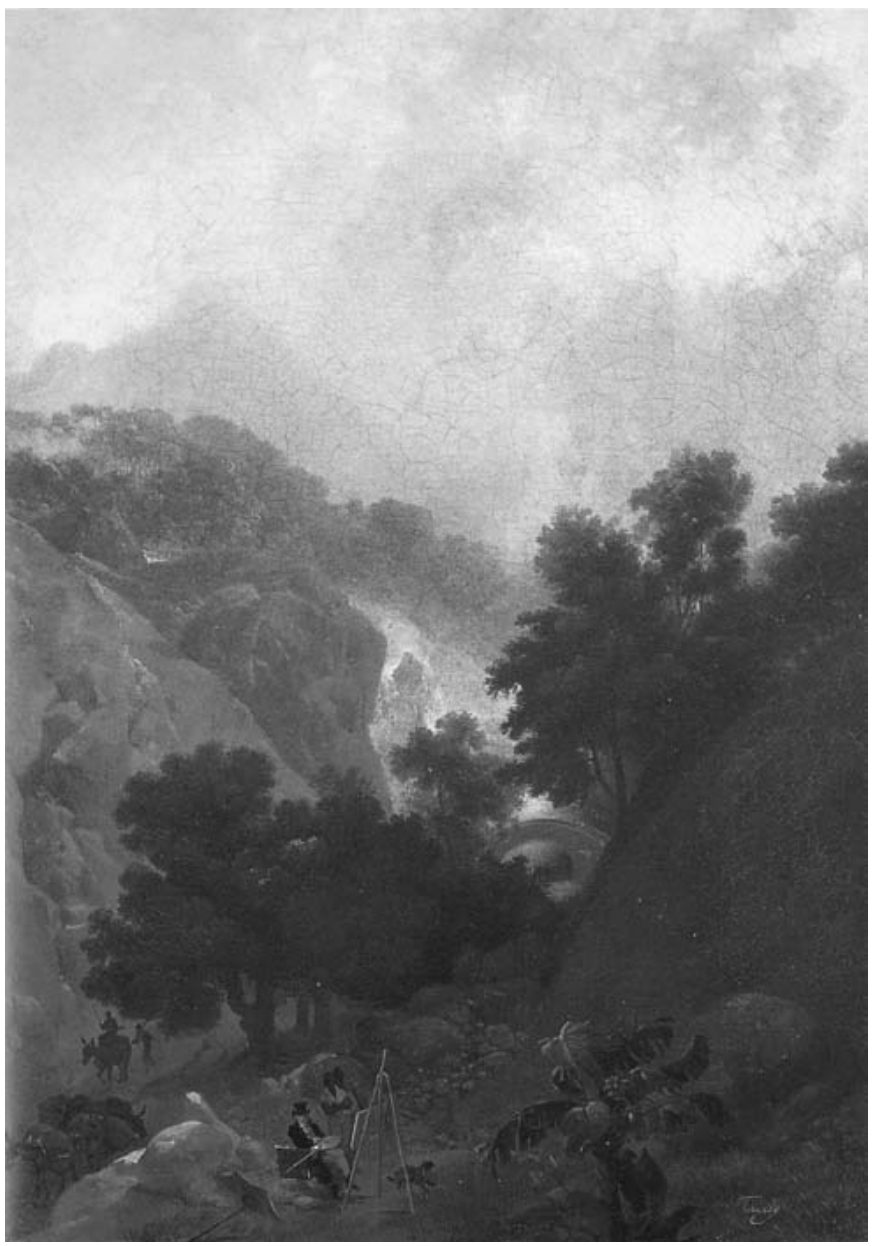

[Cascatinha da Tijuca (óleo sobre tela; $65 \times 45 \mathrm{~cm}$, Rio de Janeiro, Museu Histórico da Cidade do Rio de Janeiro)]

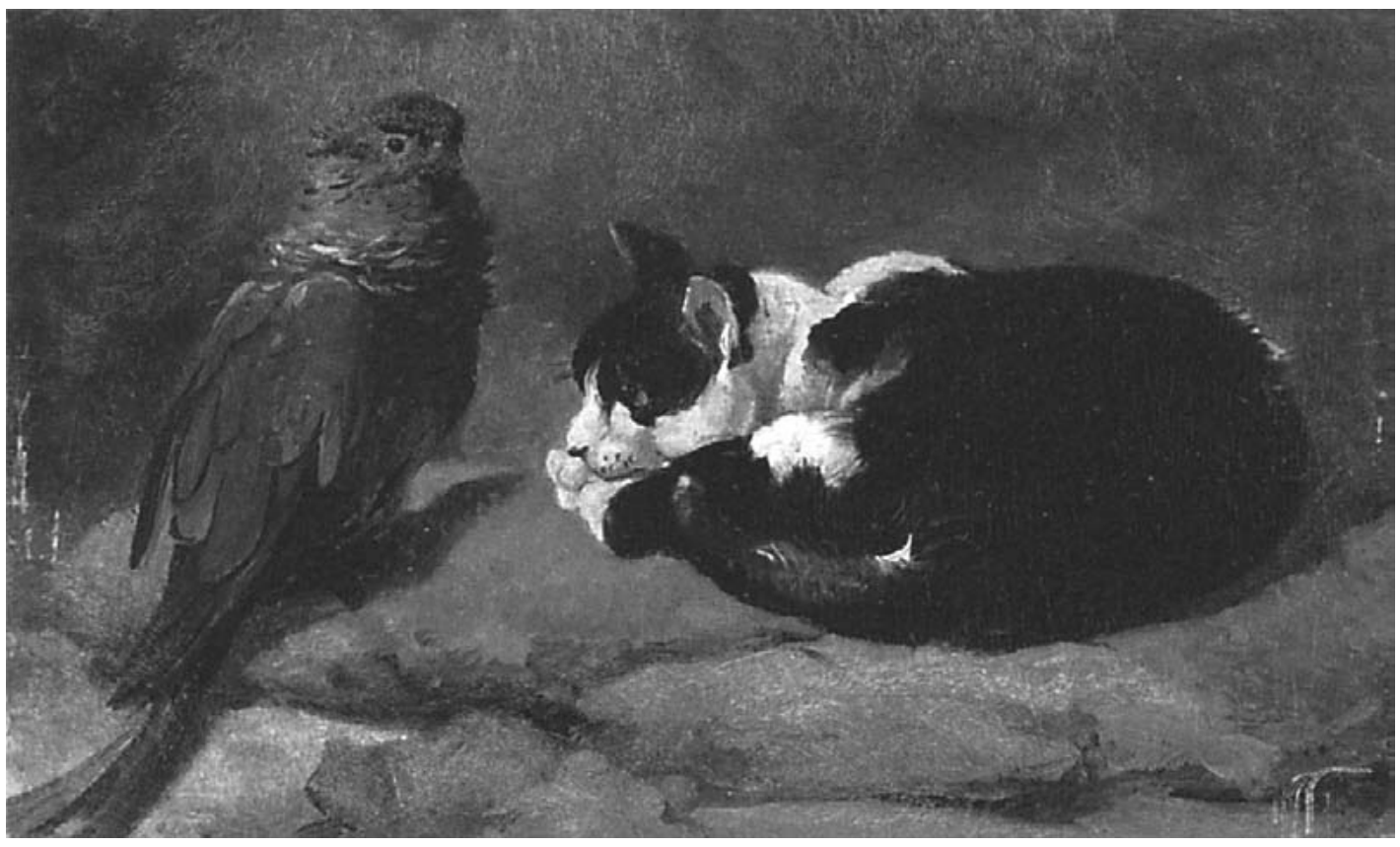

[Gato com papagaio (óleo sobre madeira; 14 por 23,1, Paris, Coleção Particular)] 
A passagem ocidental do tempo nada mais é do que uma forma particular de historicidade [...] A antropologia está aí para lembrar que tal passagem pode ser interpretada de diferentes formas [...] Vivemos a sensação de uma flecha irreversivel do tempo. Como observava Nietzsche, os modernos têm a doença da história. Querem datar tudo, porque pensam terem rompido definitivamente com o passado [...] Mas o passado permanece ou mesmo retorna ${ }^{96}$.

Estou me referindo a uma antropologia histórica da nossa própria sociedade, terreno onde situo minhas investigações. Trata-se de, à semelhança do que a etno-história realiza para outras culturas, recuperar um trabalho de "tradução para as sociedades complexas" 97. Esse tipo de antropologia nos levaria a ser capazes de nos espantar diante de formas de representar nossa própria sociedade e, por que não?, o tempo e a história. E quem sabe Keith Thomas tenha razão quando reconhece que "aqueles que estudam o passado se deparam com duas conclusões contraditórias. A primeira é que o passado era muito diferente do presente. A segunda é que ele era muito parecido" 98 .

Mas é hora de terminar, e recorro a um exemplo da literatura: Hans Castorp, personagem de $A$ montanha mágica, um jovem que narra "fatos recobertos pela pátina do tempo e na forma de um passado remoto" 99 . O cenário se concentra no sanatório Berghof, localizado na aldeia suíça de Davos-Platz, espécie de laboratório de uma Europa enferma do período entre guerras, quando se entrelaçam inquietações, ilusões e utopias... todas reunidas pela mesma doença ${ }^{100}$.

E Castorp vai ficando nesse local em que o tempo ganha outro tipo de duração. Mas deixemos Thomas Mann narrar:

[...] é necessário que as Histórias já se tenham passado. Poderíamos até dizer que, quanto mais se distanciam do presente, mais adequadas serão ao narrador, este mago que evoca o pretérito. Acontece, porém, com a História o que hoje em dia acontece com os homens e com os narradores de Histórias: ela é muito mais velha que seus anos; sua vetustez não pode ser medida por dias [...] Não é propriamente ao tempo que a História deve o seu grau de antigüidade - e com esta observação feita de passagem aludimos ao caráter problemático desse elemento misterioso ${ }^{101}$.

A história é central nesse livro, mas sua extensão não se mede por dias, e sim por esse "elemento misterioso" chamado tempo. No entanto, como o tempo "é um enigma difícil de resolver" ${ }^{102}$, o romance corre, e Castorp comprova que as sete semanas que passara lá em cima, na montanha, não lhe pareceram mais do que sete dias. Ou às vezes tudo acontecia exatamente ao contrário: já vivia naquele mesmo lugar muito mais tempo do que a realidade lhe anunciava. Segundo Thomas Mann, "uma coisa e outra eram, provavelmente, verdade: ao seu olhar retrospectivo, o tempo ali passado afigurava-se excessivamente longo como excessivamente breve. Umúnico aspecto desse tempo, entretanto, escapava-lhe: a sua duração real — admitindo ser o tempo um fenômeno natu-
[90] Relaciono, nesse sentido, entre tantas outras, as obras de Fry, P. "Febrônio Índio do Brasil", in Caminhos cruzados. São Paulo: Brasiliense, 1982; Grin Debert, G. Ideologia e populismo. São Paulo: T. A. Queiroz, 1979; Cunha, M. C. da. Negros estrangeiros. São Paulo: Brasiliense, 1979; Borges Pereira, J. B. Italianos no mundo rural paulista. $2^{-}$ ed. São Paulo: Edusp, 2002; Mott, L. Rosa Egipcíaca. Uma santa africana no Brasil. Rio de Janeiro: Bertrand Brasil, 1993; Lima, A. C. Aos fetichistas ordem e progresso. Rio de Janeiro: Dissertação de mestrado, Museu Nacional, 1989; Corrêa, M. As ilusões da liberdade. Bragança Paulista: EDUSF, 1998; Chor Maio, M. "Raça, doença e saúde pública no Brasil: um debate sobre o pensamento higienista do século XIx". Rio de Janeiro, 2004 (mimeo); Montero P. (coord.), Entre o mito e a história. $O V$ Centenário do Descobrimento da América. Rio de Janeiro: Vozes, 1996; e Ribeiro Thomaz, O. Ecos do Atlântico Sul. Rio de Janeiro/São Paulo: Editora da UFRJ/FAPESP, 2002.

[91] Gilberto Freyre, Casa-grande e senzala. $4^{\text {a }}$. ed. Rio de Janeiro: José Olympio, 1951. Refiro-me a Freyre a despeito de reconhecer que, apesar do recurso à história, o antropólogo procurava mesmo pela sincronia. Vide também, nessa tradição que retomava sempre as origens, o clássico de Bastide, R. As religiões africanas no Brasil [1960]. São Paulo: Pioneira, 1971.

[92] Estou me referindo ao livro $O$ espetáculo das raças. São Paulo: Companhia das Letras, 1993. Esse estudo é, de certa maneira, produto da reflexão realizada no Idesp, a qual resultou na coletânea organizada por Miceli, S. História das ciências sociais no Brasil. São Paulo: Vértice/ Idesp, 1989.

[93] A referência, nesse caso, é ao livro As barbas do Imperador. São Paulo: Companhia das Letras, 1998.

[94] "Entrevista com o antropólogo Eduardo Viveiros de Castro", ed. cit., p. 118.

[95] Ginzburg, C. Mitos, emblemas e sinais. São Paulo: Companhia das Letras, 1989, p. 92.

[96] Latour, B. op. cit., pp. 68-9. 
[97] Geertz, C. “Como pensamos hoje: a caminho de uma etnografia do pensamento moderno", in O saber local. Petrópolis: Vozes, 2003.

[98] Thomas, K. "Introduction", in Bremmer, Jan \& Roodenburg, $\mathrm{H}$. (eds.) A cultural history of gesture, Cambridge: Polity Press, 1991, p. 10.

[99] Mann, T. A montanha mágica. Rio de Janeiro: Nova Fronteira, 1980, p. 9.

[100] Vale a pena destacar que o escritor alemão Thomas Mann (18751955) dedicou sua obra a retratar o colapso da sociedade européia após a Primeira Guerra Mundial. Projeta-se com a saga familiar Os Buddenbrook (1901), ejá em Morteem Veneza(1912) explora os temas da decadência e da morte. Mas foi com A montanha mágica (1924) que tratou mais diretamente da desestruturação daquilo que considerava ser a civilização européia. Opositor do nazismo, deixou a Alemanha em 1933 para se fixar nos Estados Unidos em 1938. Em 1947 voltou definitivamente à Alemanha.

[101] Mann, T. op. cit., p. 9.

[102] Ibidem, p. 161.

[103] Ibidem, p. 248.

[104] Ibidem, p. 601.

[105] Benjamin, W. "Sobre o conceito de história", in Obras escolhidas. São Paulo: Brasiliense, 1985.

[106] Dumont, L. O individualismo: uma perspectiva antropológica da ideologia moderna. Rio de Janeiro: Rocco, 1985, pp. 19-20.

[107] Para essa discussão, vide Peixoto, F. "O diálogo como forma". Caxambu, XXV Encontro Anual da ANPOCS, 2001, p. 3 (mimeo).

[108] Veyne, P. Como se escreve a história. Brasília: Editora da UnB, 1982.

Recebido para publicação

em 10 de abril de 2005.

\section{NOVOSESTUDOS}

CEBRAP

n 72 , julho 2005

pp. 119-135 ral e ser lícito relacionar com ele o conceito de realidade"103. Escapava-lhe, justamente, a nossa temporalidade: o mês de outubro que estava prestes a começar, ou a objetividade dos dias impressos no calendário.

De um modo ou de outro, "o tempo escoava e seguia o seu curso [...] de forma que nenhum homem de espírito são pudesse considerá-lo História"104. Até parece que estamos diante da noção de "tempo misterioso", utilizada por Walter Benjamin: "essa imagem do passado que a história transforma em coisa sua"105. A montanha mágica permite lembrar de que maneira, também entre nós, o tempo e a história são matéria de negociação: ambíguos em sua compreensão, múltiplos nos desenlaces, vários enquanto representação.

O tema escolhido permitiu, assim, não só refazer uma certa história da antropologia, mas localizar muitas histórias: uma história que os homens fazem sem saber (como categoria analítica); uma história que os homens sabem que fazem (como disciplina); a história como elemento universal ou traço da relatividade. Por fim, ajudou a problematizar nossas concepções de tempo e história. Como revela Dumont, "a tese complementar que falta demonstrar, ou defender, é que, inversamente, uma perspectiva antropológica pode permitir-nos conhecer melhor o sistema moderno de idéias e valores, sobre o qual acreditamos saber tudo pelo simples fato de ser nele que pensamos e vivemos"106.

Parece-me, portanto, oportuno desconfiar de definições disciplinares que se assentam, exclusivamente, num método ou num objeto. O que define a antropologia é antes uma questão ou uma postura que, nos termos de Merleau-Ponty, "diz respeito à própria natureza da reflexão antropológica que, ao levar a sério a alteridade, cria um espaço de encontro entre o 'eu' e o 'outro'"107. Como ciência da alteridade e da diversidade, a antropologia permite transpor conceitos e fazer a reflexão incidir sobre nós mesmos. Noutras palavras, se a antropologia deve se debruçar sobre o que é considerado "nativamente" relevante, não pode deixar escapar a centralidade que a história ocupa em nosso pensamento: ela é parte fundamental das grandes narrativas sociais e da forma de nos auto-representar, costurando eventos. E, como mostrou Paul Veyne, "um evento é apenas o que se destaca sobre um fundo de uniformidade; é uma diferença", da mesma maneira como a "história no singular, e com maiúscula, no limite não existe"108.

Esses são os desafios de uma "antropologia histórica", na perspectiva de Bloch; de uma "história antropológica", na versão de Sahlins, ou de uma "antropologia da história", expressão com que iniciei este ensaio e que implica privilegiar, como quer Lévi-Strauss, várias historicidades. Não se trata de jogar com palavras, mas antes de assinalar uma questão tão complexa como antiga: afinal, somos todos nativos de nossas muitas temporalidades. Ou, como diria Thomas Mann: "A História é muito mais velha que seus anos".

LILIA K. MORITZ SCHWARZ é professora titular do Departamento de Antropologia Social da USP. 